\title{
The C-terminal tail of the Hedgehog receptor Patched regulates both localization and turnover
}

\author{
Xingwu Lu, Songmei Liu, and Thomas B. Kornberg ${ }^{1}$ \\ Department of Biochemistry and Biophysics, University of California at San Francisco, San Francisco, California 94143, USA
}

\begin{abstract}
Patched (Ptc) is a membrane protein whose function in Hedgehog $(\mathrm{Hh})$ signal transduction has been conserved among metazoans and whose malfunction has been implicated in human cancers. Genetic analysis has shown that Ptc negatively regulates $\mathrm{Hh}$ signal transduction, but its activity and structure are not known. We investigated the functional and structural properties of Drosophila Ptc and its C-terminal domain (CTD), 183 residues that are predicted to reside in the cytoplasm. Our results show that Ptc, as well as truncated Ptc deleted of its CTD, forms a stable trimer. This observation is consistent with the proposal that Ptc is structurally similar to trimeric transporters. The CTD itself trimerizes and is required for both Ptc internalization and turnover. Two mutant forms of the CTD, one that disrupts trimerization and the other that mutates the target sequence of the Nedd4 ubiquitin ligase, stabilize Ptc but do not prevent internalization and sequestration of Hh. Ptc deleted of its CTD is stable and localizes to the plasma membrane. These data show that degradation of Ptc is regulated at a step subsequent to endocytosis, although endocytosis is a likely prerequisite. We also show that the CTD of mouse Ptc regulates turnover.
\end{abstract}

[Keywords: Patched; Hedgehog; Hedgehog receptor; protein multimerization; trimer; protein turnover]

Supplemental material is available at http://www.genesdev.org.

Received June 20, 2006; revised version accepted July 31, 2006.

Hedgehog ( $\mathrm{Hh})$ signaling is essential to the development of many organs and tissues, and is implicated in many human diseases. Its role and mechanism are broadly conserved among metazoans. Target cells deploy two transmembrane proteins to receive and regulate Hh signalsPatched (Ptc) and Smoothened (Smo)-and genetic evidence suggests that the activities of these proteins are functionally linked. Smo is a seven-transmembrane domain protein that is essential to transduce the Hh signal (Alcedo et al. 1996; van den Heuvel and Ingham 1996), but Smo does not apparently function as a receptor. Instead, Ptc is proposed to be the Hh receptor (Ingham et al. 1991; Chen and Struhl 1996; Marigo et al. 1996; Stone et al. 1996; Fuse et al. 1999), and to inhibit Smo unless bound by Hh. Understanding the processes by which Ptc responds to $\mathrm{Hh}$ and gates signal transduction is the key to deciphering the mechanism of Hh signaling.

Ptc proteins have been identified in a number of species, and their roles in Hh signal transduction appear to be conserved. Ptc proteins are present at the highest levels in cells that are active in Hh signal transduction, where they are up-regulated in response to Hh /Capdev-

${ }^{1}$ Corresponding author.

E-MAIL tkornberg@biochem.ucsf.edu; FAX (415) 514-1470.

Article is online at http://www.genesdev.org/cgi/doi/10.1101/gad.1461306. ila et al. 1994a; Tabata and Kornberg 1994; Ingham and Fietz 1995; Goodrich et al. 1996; Marigo et al. 1996). Molecular evidence for Hh binding has been provided by studies showing that vertebrate Sonic Hh (Shh) binds to cells expressing vertebrate Ptc (Marigo et al. 1996; Stone et al. 1996; Fuse et al. 1999). Although equivalent data for Drosophila Hh and Drosophila Ptc has not been reported, genetic studies in Drosophila show that Ptc acts downstream from $\mathrm{Hh}$ to regulate signaling activity (Ingham 1993; Tabata and Kornberg 1994; Ramirez-Weber et al. 2000) and that Ptc and Hh colocalize in a punctate distribution in Hh-receiving cells (Bellaiche et al. 1998; Burke et al. 1999; Ramirez-Weber et al. 2000; Martin et al. 2001; Strutt et al. 2001). Genetic studies also indicate that up-regulating Ptc expression in Hh-receiving cells functions to sequester $\mathrm{Hh}$, creating a barrier to further movement that limits the range of Hh action /Chen and Struhl 1996). Localization of Ptc to multivesicular bodies and endosomes (Capdevila et al. 1994b; Torroja et al. 2004) and removal of Ptc from the plasma membrane upon exposure to Hh (Denef et al. 2000; Zhu et al. 2003) support the proposition that Ptc scavenges Hh by ferrying it through the endocytic pathway.

It is unclear how Ptc carries out its other important roles: inhibiting Smo in the absence of Hh and activating signal transduction when Hh is present. The existence of 
Drosophila Ptc mutants that sequester and endocytose Hh but fail to inhibit Smo in the absence of Hh /Chen and Struhl 1996; Martin et al. 2001; Strutt et al. 2001; Hime et al. 2004) reveals that Smo inhibition can be uncoupled from Hh sequestration. The finding that Ptc internalization is not required for signal transduction (Torroja et al. 2004) suggests that an activity of Ptc at or near the cell surface is essential for pathway activation.

Hydropathy and BLAST (Altschul et al. 1990) analyses predict that Ptc proteins have 12 transmembrane domains and are structurally similar to a RND family of channels and transporters (Tseng et al. 1999). Included in the family are NPC1, the protein encoded by the Niemann-Pick C1 gene (Carstea et al. 1997; Loftus et al. 1997) that transports fatty acids across membranes, and the proton-driven Escherichia coli AcrB protein, an ancestral relative of NPC-1 that pumps a variety of charged and uncharged substances out of cells (Nikaido and Zgurskaya 2001). Interestingly, Ptc activity is impaired by mutations in residues that are conserved in and required for activity of the several bacterial RND transporters (Taipale et al. 2002) or of NPC1 (Martin et al. 2001; Strutt et al. 2001). Several of these transporters are known to have an oligomeric structure, and genetic analysis of Drosophila ptc is consistent with the possibility that Ptc is also a multimer. In particular, interallelic complementation has been observed between several Drosophila ptc alleles, interactions that may be a consequence of direct cooperation between partially impaired subunits (Johnson et al. 2000; Mullor and Guerrero 2000; Martin et al. 2001; Vegh and Basler 2003; Torroja et al. 2004). These studies raise the intriguing possibility that Ptc is a multisubunit transporter whose activity indirectly regulates localization and function of Smo.

Previous structure/function studies of Ptc found that $\mathrm{C}$-terminal terminal deletions reduce $\mathrm{Hh}$ signaling when expressed in Hh-expressing cells, and activate signaling in a ligand-independent manner in target cells (Johnson et al. 2000). These phenotypes suggest that the C-terminal domain (CTD) is required to inhibit Smo, but not to sequester Hh. The lethal ptc $c^{13}$ mutant has similar properties; it has a missense mutation (E1172K) in a conserved CTD residue (Strutt et al. 2001). The molecular basis for these phenotypes has not been determined.

We now show that Ptc exists as a trimer, and that Ptc mutant protein lacking a CTD can also trimerize. Ptc protein lacking a CTD localizes to the plasma membrane where it can associate directly with wild-type protein, but it does not internalize in the presence of Hh. CTDdeleted protein is more stable than wild type, and we identified a sequence in the CTD that is both a target for the Nedd4 ubiquitin ligase and is essential for turnover. The CTD can independently trimerize, and mutations in the CTD that abrogate trimerization stabilize Ptc protein but do not prevent Hh-induced internalization. These findings reveal that Ptc turnover is regulated subsequent to internalization, and indicate that the phenotypes of CTD mutants are in part the consequence of interference with wild-type Ptc.

\section{Results}

\section{The Ptc C-terminal tail is an oligomerization domain}

To investigate whether the function of the Ptc CTD involves interactions with other cellular components, we carried out a yeast two-hybrid screen to isolate Drosophila cDNAs encoding proteins that bind to the Ptc CTD. Three of the cDNA clones that scored in the screen encode the Ptc CTD (Table 1), a result that suggests that the CTD self-oligomerizes. To evaluate this apparent self-association, the behavior of the CTD was tested by three independent methods that measure protein-protein interactions. (1) Glutathione agarose-affinity chromatography was used to demonstrate that the CTD (residues 1104-1286) synthesized in vitro binds to a chimeric Glutathione-S-transferase (GST)-CTD protein (Fig. 1A) Binding was specific to the CTD domain, and was not observed when GST was fused to unrelated protein domains (from $\mathrm{Hh}$ or the estrogen-related receptor [CG7404]). (2) Immunoprecipitation experiments revealed selective binding of GST-CTD to Myc-CTD when both are coexpressed in S2 cells (Fig. 1B). (3) Size measurements provided further evidence for stable CTD oligomers. We expressed and purified the Maltose-Binding Protein (MBP) as well as a MBP-CTD fusion, and we estimated their respective molecular weights by size-exclusion gel chromatography and by electrophoresis. Whereas MBP eluted at a volume expected for monomeric MBP (40.4 kDa), the 60.5-kDa MBP-CDT fusion eluted at a volume predicted for a $182-\mathrm{kDa}$ protein (Fig. 1C). Under native conditions, MBP-CTD electrophoresed at a rate consistent with this molecular weight

Table 1. Yeast two-hybrid assays of four Ptc-CTD derivatives as well as control constructs with HhN and ERR

\begin{tabular}{|c|c|c|c|c|c|c|}
\hline & PGAD424 & $\begin{array}{c}\text { pGAD424- } \\
\text { CTD }^{\text {WT }}\end{array}$ & $\begin{array}{l}\text { pGAD424- } \\
\text { CTD }^{1 / 2 C(N)}\end{array}$ & $\begin{array}{l}\text { pGAD424- } \\
\text { CTD }^{1 / 2 C(C)}\end{array}$ & $\begin{array}{c}\text { pGAD424- } \\
\text { CTD }^{3 P}\end{array}$ & $\begin{array}{c}\text { pGAD424- } \\
\text { ERR }\end{array}$ \\
\hline pGBT9 & - & - & - & - & - & - \\
\hline pGBT9-CTD ${ }^{\mathrm{WT}}$ & - & + & - & + & - & - \\
\hline pGBT9-CTD $^{1 / 2 C(N)}$ & - & - & - & - & - & - \\
\hline pGBT9-CTD $^{1 / 2 C(C)}$ & - & + & - & + & - & - \\
\hline pGBT9-CTD ${ }^{3 P}$ & - & - & - & - & - & - \\
\hline pGBT9-HhN & - & - & - & - & - & - \\
\hline
\end{tabular}

$\mathrm{CTD}^{1 / 2 \mathrm{C}(\mathrm{N})}$ and $\mathrm{CTD}^{1 / 2 \mathrm{C}(\mathrm{C})}$ represent the $\mathrm{N}$ - and $\mathrm{C}$-terminal halves, respectively. $(+)$ growth on selective medium; $(-)$ poor or no growth. 
A

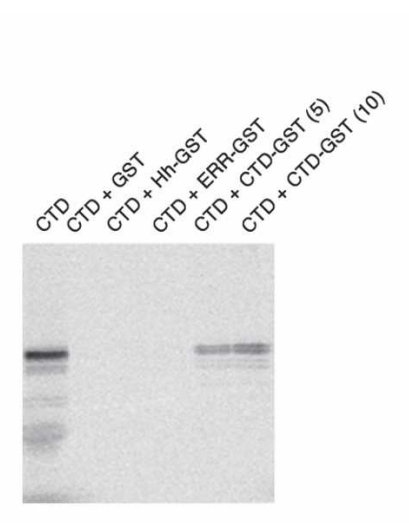

B

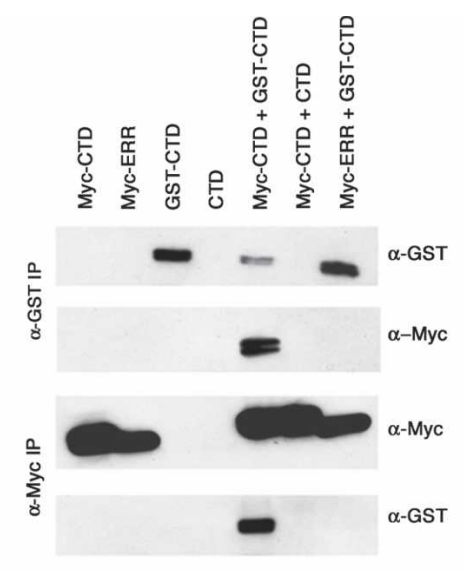

C
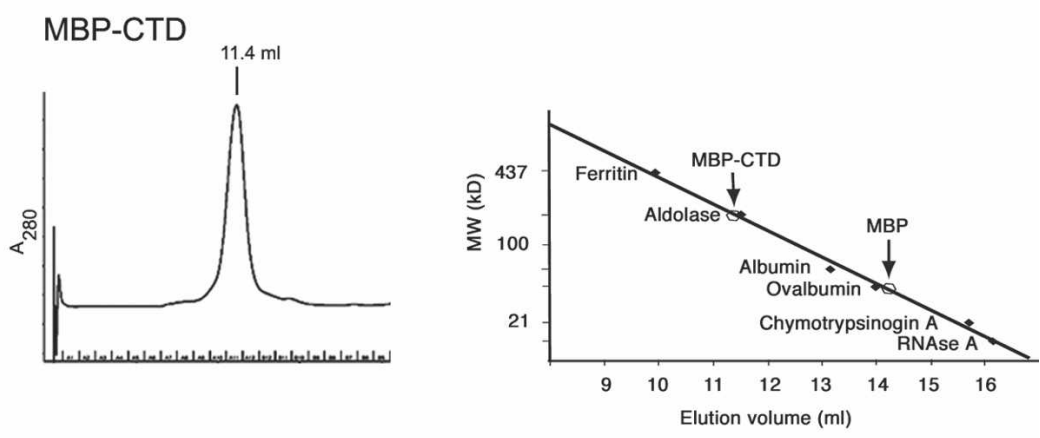

D

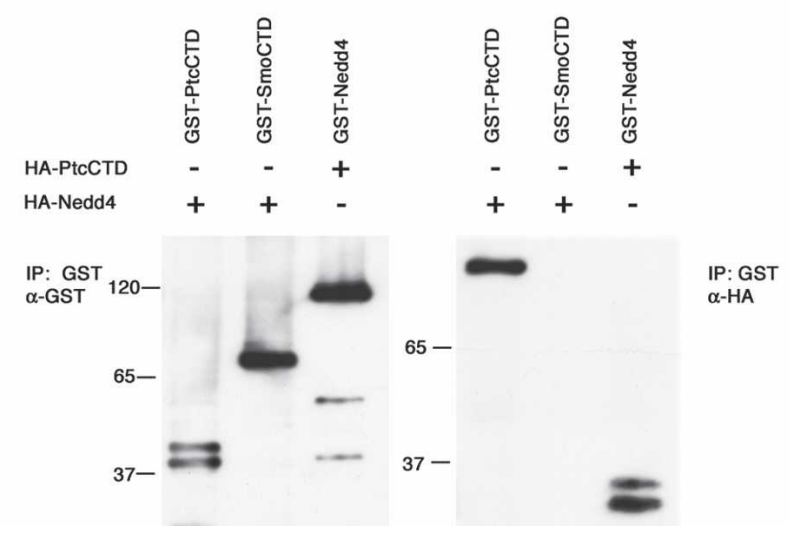

Figure 1. Self-association of the CTD. $(A)$ Autoradiogram after PAGE analysis of ${ }^{35} \mathrm{~S}$ CTD produced by in vitro translation either before (CTD) or after incubation with glutathione beads (CTD + GST proteins) that were bound by bacteria-generated GST or GST fusions proteins, as indicated. ERR is the cytoplasmic domain of the estrogen receptor-related protein (CG7404) (Ostberg et al. 2003), and was used as an unrelated control. Pull-downs were with $10-\mu \mathrm{g}$ beads except for lane $5(5 \mu \mathrm{g})$. $(B)$ $\alpha$-Myc and $\alpha$-GST immunoprecipitates of S2 cell extracts containing Myc-tagged CTD, Myc-tagged ERR, and GST-CTD fusion proteins, fractionated by PAGE and Western blots and probed with $\alpha$-Myc and $\alpha$-GST antibodies as indicated on the right. (Lane 5) Coimunoprecipitation was only apparent with Myc-CTD and GSTCTD. (C) Gel exclusion chromatography of purified MBP (40.4 kDa) and MBP-CTD $(60.5 \mathrm{kDa})$ fusion proteins yielded single peaks of $280-\mathrm{nm}$ absorbance at volumes expected for a MBP monomer and a MBPCTD trimer: $14.3 \mathrm{~mL}$ and $11.4 \mathrm{~mL}$, respectively. Molecular weight standards eluted as follows: ferritin (440 kDa, $9.7 \mathrm{~mL})$; aldolase $(158 \mathrm{kDa}, 11.7 \mathrm{~mL})$; albumin $(67$ $\mathrm{kDa}, 13.3 \mathrm{~mL}$ ); ovalbumin (43 kDa, 14.1 $\mathrm{mL})$; chymotrypsinogen A (25 kDa, 15.2 $\mathrm{mL})$; and RNAse A (13.7 kDa, $16.3 \mathrm{~mL})$. (D) Nedd4 coimmunoprecipitated with the Ptc CTD (residues 1104-1286) but not with the CTD of Smo (residues 559-1036). estimate (Supplementary Fig. 1C). We conclude that that the MBP-CTD fusion protein exists as a trimer and that self-association of the CTD is both specific and stable.

To better define the domain required for trimerization, the CTD was subdivided into $\mathrm{N}$-terminal (residues 1104-1180) and C-terminal halves (residues 1181-1286). Yeast two-hybrid experiments revealed that a peptide consisting of the $106 \mathrm{C}$-terminal residues associated with itself and with the entire 183 residue CTD, whereas the $\mathrm{N}$-terminal 77 residues of the CTD did not score in the two-hybrid assay with either itself or with the entire CTD (Table 1). Examination of the sequence of the Cterminal region identified threonines T1260, T1263, and
T1265 as residues that are conserved in both vertebrate and invertebrate Ptc proteins, and modeling studies (data not shown) predicted that they might be critical to the secondary structure of the C-terminal part of the CTD. We generated a mutant peptide that substitutes three proline residues at these positions (T1260P, T1263P, and T1265P) and expressed the mutant CTD in the yeast two-hybrid system. No interaction was observed with either the full-length CTD ${ }^{\mathrm{WT}}$ or with the wild-type 106 residue $\mathrm{C}$-terminal peptide. These results suggest that the $106 \mathrm{C}$-terminal residues of the CTD are necessary for self-association of the CTD, and that the three proline substitutions in the mutant CTD interfere with sequence or structural requirements for oligomerization. 
Oligmerization of the Ptc CTD is essential to Ptc function

We next sought to determine whether CTD oligomerization is important to Ptc function. Johnson et al. (2000) reported that Ptc deleted of $156 \mathrm{C}$-terminal residues $\left(\mathrm{Ptc}^{1130 \mathrm{X}}\right)$ reduces $\mathrm{Hh}$ signaling if it is expressed in Hhexpressing cells. They also reported that $\mathrm{Ptc}^{1130 \mathrm{x}}$ has dominant negative activity, relieving Smo inhibition and promoting target gene activation in a ligand-independent manner in cells that do not normally receive $\mathrm{Hh}$. This phenotype suggests that $\mathrm{Ptc}^{1130 \mathrm{X}}$ interferes with $\mathrm{Ptc}^{\mathrm{WT}}$. Furthermore, $\mathrm{Ptc}^{1130 \mathrm{X}}$ was incapable of complementing ptc mutants in an embryo rescue assay. We created two ptc alleles with mutations that alter the CTD. The first $\left(\mathrm{Ptc}^{\Delta 1 / 2 \mathrm{C}}\right)$ deletes the $106 \mathrm{C}$-terminal residues. The second allele $\left(\mathrm{Ptc}^{3 \mathrm{P}}\right)$ has the three threonine-to-proline mutations: T1260P, T1263P, and T1265P. We made transgenic flies carrying UAS expression constructs for both $\mathrm{Ptc}^{\Delta 1 / 2 \mathrm{C}}$ and $\mathrm{Ptc}^{3 \mathrm{P}}$ and tested them in several independent assays.

In all tests, the phenotypes of both $p t c^{\Delta 1 / 2 C}$ and $p t c^{3 P}$ were indistinguishable from those described for $p t c^{1130 X}$ (Johnson et al. 2000). (1) In assays for rescue of ptc mutant embryos, we observed partial rescue after ectopic expression of $\mathrm{Ptc}^{\mathrm{WT}}$ (81/160 mutant embryos), but we observed no rescue after ectopic expression of $\mathrm{Ptc}^{\Delta 1 / 2 \mathrm{C}}$ (0/54 embryos). (2) When $\mathrm{Ptc}^{\Delta 1 / 2 \mathrm{C}}$ was expressed throughout the wing discs (using T80 Gal4, which expresses constitutively in discs), the anterior compartments of $p t c^{B 98} /+$ wings were enlarged and had extensive vein defects (Fig. 2E,F). Similar effects were observed with Ptc $^{1130 x}$ (data not shown). Characterizations re-

\section{A}

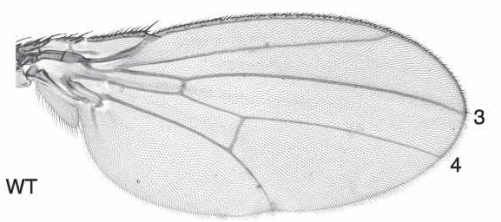

C

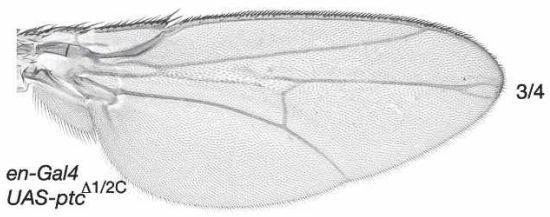

E

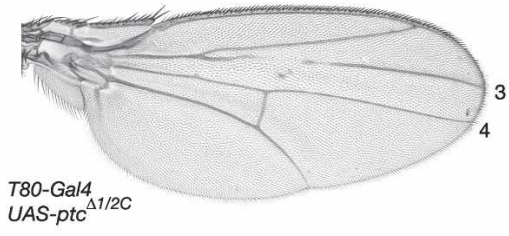

ported by Johnson et al. (2000) and Hime et al. (2004) suggest that these defects are a consequence of ligandindependent activation of Hh target genes. (3) Expression of either $\mathrm{Ptc}^{\Delta 1 / 2 \mathrm{C}}$ or $\mathrm{Ptc}^{3 \mathrm{P}}$ in the posterior compartment of wing disc caused extreme reductions in the central wing region (Fig. 2C,D). Expression of $\mathrm{Ptc}^{\mathrm{WT}}$ in the wing disc P compartment caused a similar, but less extreme reduction in the intervein region between veins 3 and 4 (Fig. 2B), a phenotype that has been attributed to reduced $\mathrm{Hh}$ signaling caused by sequestration of $\mathrm{Hh}$. The greater severity of the $\mathrm{ptc}^{\Delta 1 / 2 \mathrm{C}}$ or $\mathrm{ptc}^{3 \mathrm{P}}$ phenotypes was common to all transgenic lines that we tested, and to ptc ${ }^{1130 X}$ (Johnson et al. 2000). We conclude that $\mathrm{Ptc}^{\Delta 1 / 2 \mathrm{C}}$ and $\mathrm{Ptc}^{3 \mathrm{P}}$ reduce the function of the CTD in ways that are comparable to the Ptc ${ }^{1130 x}$ CTD deletion.

\section{The CTD regulates turnover of the Ptc protein}

To investigate the basis for the more severe phenotypes that result when $\mathrm{Ptc}^{\Delta 1 / 2 \mathrm{C}}$ is expressed in the P compartment, real-time PCR and Western analyses were carried out. ptc mRNA from en-Gal4, UAS-ptc ${ }^{W T}$, and en-Gal4, $U A S-p t c^{\Delta 1 / 2 C}$ wing discs were compared with control discs to determine if levels of $p t c^{\Delta 1 / 2 C}$ RNA was similar to or different from $p t c^{W T}$ RNA. RT-PCR assays revealed an approximately equivalent increase in both $\left(p t c^{W T}, 3.1\right.$ times; $p t c^{\Delta 1 / 2 C}$, four times). Although we do not know if the marginally higher amount of $p t c^{\Delta 1 / 2 C}$ mRNA was responsible for the more extreme wing phenotypes, the differences in $\mathrm{Ptc}^{\mathrm{WT}}$ and $\mathrm{Ptc}^{\Delta 1 / 2 \mathrm{C}}$ protein levels were much greater, 2.1 times and 7.8 times, respectively (Fig. $3 \mathrm{~A})$. Discs expressing $p t c^{\Delta 1 / 2 \mathrm{C}}$ therefore have signifi-
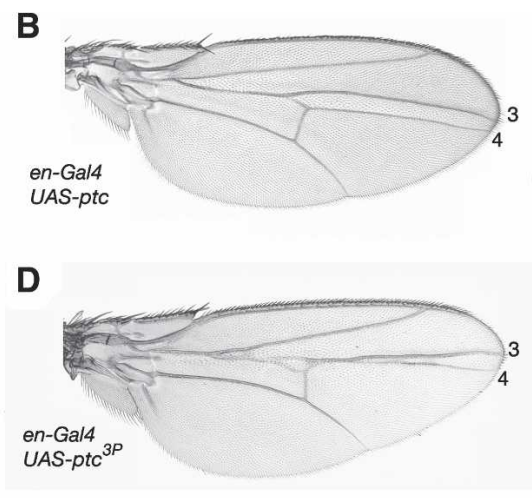

$\mathbf{F}$

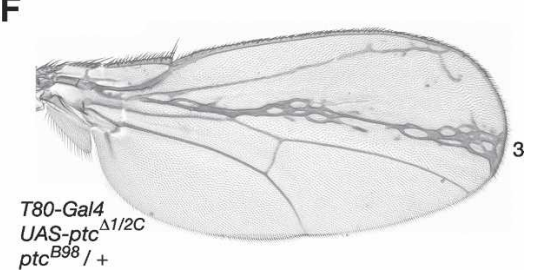

Figure 2. Inhibition of Hh signaling by ectopic Patched expression. Wings from wild-type $(A)$ and transgenic $(B-F)$ flies expressing wild-type or mutant Ptc proteins. Wing veins 3 and 4 are indicated. $(B-D)$ Ptc expression in the posterior compartment reduces the 3-4 intervein region, a phenotype that is more extreme when protein with mutant CTD is expressed. Reducing the level of wild-type $\operatorname{Ptc}(F)$ increases Hh pathway activation in the anterior compartment when $\operatorname{Ptc}^{\Delta 1 / 2 \mathrm{C}}$ is expressed uniformly $(E, F)$. Wings of $p t c^{B 98} /+$ flies were indistinguishable from wild type (not shown). All wings are shown anterior up. 
A

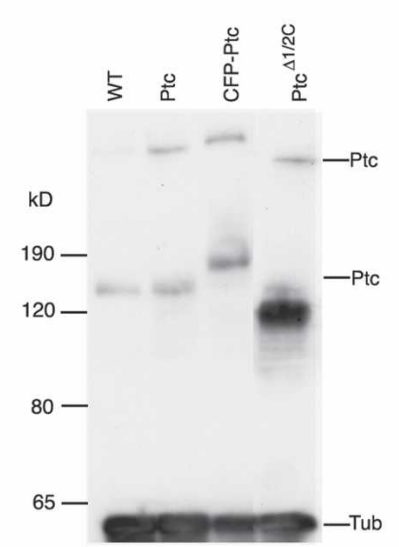

B

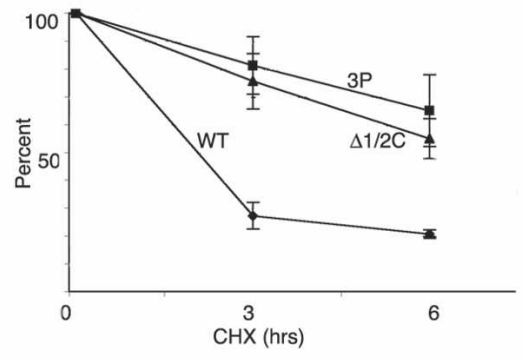

D

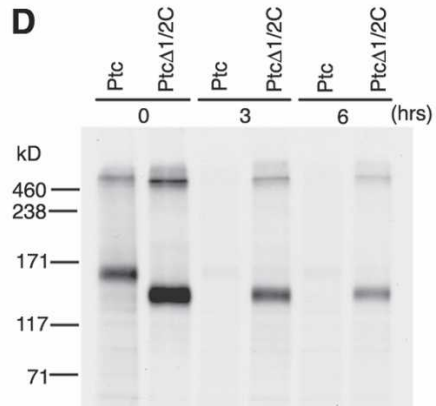

C

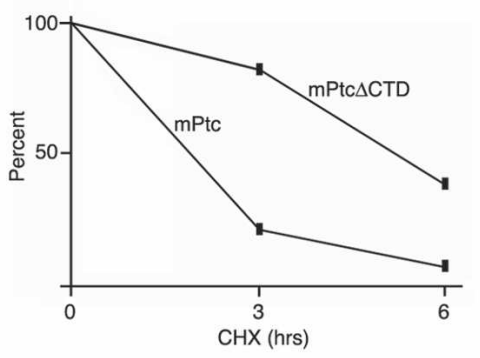

$\mathbf{E}$

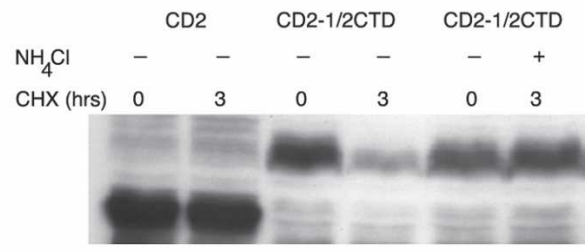

Figure 3. The CTD regulates turnover of Patched protein. $(A)$ Western blot analysis of wild-type wing discs and wing discs expressing the indicated proteins under the control of en-Gal4. Thirty discs in each lane. $(B)$ Quantification of wild-type Ptc, Ptc ${ }^{\Delta 1 / 2 C}$, and Ptc ${ }^{3 P}$ by Western analysis in transfected S2 cells after incubation in the presence of cycloheximide for the indicated times. $(C)$ Quantification of wild-type mouse Ptc and mouse Ptc ${ }^{\Delta \mathrm{CTD}}$ in transfected COS-7 cells after incubation in the presence of cycloheximide for the indicated times. $(D)$ Pulse-chase analysis of Ptc and $\mathrm{Ptc}^{\Delta 1 / 2 \mathrm{C}}$ in transfected S2 cells labeled with ${ }^{35}$ S-methionine. $(E)$ Western blot analysis of S2 cells expressing CD2 or CD2-CTD and incubated in the presence or absence of cycloheximide for $3 \mathrm{~h}$ with or without $\mathrm{NH}_{4} \mathrm{Cl}$. Blot was probed with $\alpha$-CD2 antibody.

cantly higher levels of $\mathrm{Ptc}^{\Delta 1 / 2 \mathrm{C}}$ protein, and we suggest that these greater amounts of protein lead to the more severe phenotypes.

We carried out several tests to determine why the level of $\mathrm{Ptc}^{\Delta 1 / 2 \mathrm{C}}$ was elevated in discs in which the encoding mRNA was not increased a comparable amount. To examine the relative stability of the $\mathrm{Ptc}^{\mathrm{WT}}, \mathrm{Ptc}^{\Delta 1 / 2 \mathrm{C}}, \mathrm{Ptc}^{3 \mathrm{P}}$, $\mathrm{Ptc}^{\Delta \mathrm{C}}$ (deleted of residues 1104-1286) and $\mathrm{Ptc}^{1130 \mathrm{X}}$ (deleted of residues 1131-1286) proteins, S2 cells were transfected with constructs that express each of these Ptc proteins, and Ptc protein levels were monitored after addition of the inhibitor of protein synthesis, cycloheximide. Similar results were obtained for each of the mutant proteins. Results for $\mathrm{Ptc}^{\mathrm{WT}}, \mathrm{Ptc}^{\Delta 1 / 2 \mathrm{C}}$ and $\mathrm{Ptc}^{3 \mathrm{P}}$ are shown in Figures 3B and Supplementary Figure 2. Little $\mathrm{Ptc}^{\mathrm{WT}}$ was detectable after 3-h incubation in the presence of cycloheximide, indicating that the half-life of Ptc protein is $<2 \mathrm{~h}$ under these conditions. In contrast, both $\mathrm{Ptc}^{\Delta 1 / 2 \mathrm{C}}$ and $\mathrm{Ptc}^{3 \mathrm{P}}$ remained abundant, and the stability of the mutant proteins was more than three times that of the wild-type protein. The half-lives of the mutant proteins were in excess of $6 \mathrm{~h}$. The conclusion that the CTD mutants are more stable than wild type was confirmed by pulse-chase analysis (Fig. 3D), and experiments with $\mathrm{Ptc}^{\Delta \mathrm{C}}$ and $\mathrm{Ptc}^{1130 \mathrm{X}}$ indicated that these proteins are similarly stable (data not shown). Analysis of $\mathrm{Ptc}^{\mathrm{WT}}$ and $\mathrm{Ptc}^{\Delta 1 / 2 \mathrm{C}}$ in cycloheximide-treated $\mathrm{S} 2$ cells exposed to $\mathrm{Hh}$ did not detect either a Hh-dependent increase or decease of either protein.

To determine if the sequences in the CTD might contain sequences that direct Ptc to a degradative pathway, we asked if the CTD confers instability to a heterologous protein. Two forms of the transmembrane domain of rat CD2 were tested: $\mathrm{CD} 2$ alone and $\mathrm{CD} 2$ with a C-terminal fusion to the $106 \mathrm{C}$-terminal Ptc residues (CD2-1/ 2CTD). As shown in Figure 3E, the levels of CD2 were undiminished after $3 \mathrm{~h}$ in the presence of cycloheximide, indicating that the transmembrane domain of $\mathrm{CD} 2$ is stable in S2 cells. In contrast, the levels of CD2-1/2CTD were reduced by $>80 \%$ after $3 \mathrm{~h}$ of incubation. Inclusion of $\mathrm{NH}_{4} \mathrm{Cl}$, which inhibits lysosomal protein hydrolysis (Kwok and Richardson 2004), arrested loss of CD2-1/ 2CTD.

\section{The PPXY motif in the CTD is essential for turnover}

To identify the sequences in the CTD that mediate turnover, we first tested the role of a putative PEST domain in the C-terminal half of the CTD, residues 1220-1253 that include many prolines, glutamates, serines, and threonines (Rogers et al. 1986). Deletion of these residues did not alter the half-life of Ptc $\left(\mathrm{Ptc}^{\Delta 1220-1253}\right)$ in S2 cells treated with cycloheximide (data not shown), indi- 
cating that residues $1240-1273$ do not regulate Ptc stability under these conditions.

We next examined the role of residues 1220-1253, a PPAY sequence that might be a target for a ubiquitin ligase. PPXY motifs are predicted to bind HECT and WW domain ubiquitin ligases such as the Drosophila Nedd4 protein, and such ubiquitin ligases can regulate trafficking of endocytic cargo (Hicke and Dunn 2003). In addition, since, a direct interaction between Ptc and Nedd4 was previously detected in a large-scale two-hybrid screen (Formstecher et al. 2005), we tested whether residues 1206-1209 affect Ptc turnover. We first confirmed a direct association of the Ptc CTD with Nedd4 by coimmunoprecipitation studies of S2 cells (Fig. 1D), suggesting that Nedd4 can recognize the PPAY motif in the Ptc CTD. To determine if the PPAY motif is necessary for Nedd4 binding and if Ptc turnover is dependent upon the PPAY sequence, a Y1209A Ptc mutant (PPAY to PPAA) was generated. A CTD construct bearing this mutation $\left(\mathrm{CTD}^{\mathrm{PPAA}}\right)$ scored in a yeast two-hybrid assay with $\mathrm{CTD}^{\mathrm{WT}}$, but in contrast to CTD ${ }^{\mathrm{WT}}, \mathrm{CTD}^{\text {PPAA }}$ did not interact with either Nedd4 or the PPXY-binding portion of Nedd4 that contains the three WW domains (Table 2). These results indicate that the PPAA mutation abrogated binding of Nedd4 with the Ptc CTD, but did not affect trimerization. Expression of $\mathrm{Ptc}^{\mathrm{PPAA}}$ in the Hhexpressing cells of the wing disc reduced Hh signaling in a manner comparable to Ptc ${ }^{\mathrm{WT}}$ (data not shown), indicating that its capacity to sequester $\mathrm{Hh}$ was also unaffected. However, the relative stability of $\mathrm{Ptc}^{\text {PPAA }}$ was altered, as assayed in cycloheximide-treated S2 cells. In contrast to Ptc ${ }^{\mathrm{WT}}$, whose half-life was $<2 \mathrm{~h},>55 \%$ of the Y1209A mutant protein remained after $4 \mathrm{~h}$ of treatment. The measured stability of the Y1209A mutant protein (half-life $\sim 4-5 \mathrm{~h}$ ), although greater than wild type (halflife $<2 \mathrm{~h}$ ), was less than either Ptc ${ }^{\Delta 1 / 2 \mathrm{C}}$ or Ptc ${ }^{3 \mathrm{P}}$ (half-life $>6 \mathrm{~h})$. We conclude that the PPAY motif contributes to, but is not solely responsible for, Ptc turnover in these cells.

\section{The CTD regulates the localization of Ptc protein}

When cells are exposed to Hh, the steady-state distribution of Ptc changes from predominantly cell surface to predominantly intracellular, and the proportion of Ptc that can be detected at the cell surface is comparatively lower (Denef et al. 2000; Zhu et al. 2003; Nakano et al. 2004). To determine if mutations that alter the CTD also affect subcellular localization, we expressed $\mathrm{Ptc}^{\Delta 1 / 2 \mathrm{C}}$ in larval salivary glands where, as Zhu et al. (2003) and
Hime et al. (2004) reported, Hh-induced changes in Ptc distribution can be monitored by direct visual examination. As shown in Figure 4A-D, GFP-Ptc ${ }^{\mathrm{WT}}$ and GFP$\mathrm{Ptc}^{\Delta 1 / 2 \mathrm{C}}$ were distributed in a similar manner in the absence of Hh, prominently at the surface of cells as well as internally. In the presence of $\mathrm{Hh}$, however, the distribution of GFP-Ptc ${ }^{\mathrm{WT}}$ changed, and most of the GFP fluorescence was intracellular. In contrast, the distribution of GFP-Ptc ${ }^{\Delta 1 / 2 C}$ did not change, and most of the GFP fluorescence remained at the plasma membrane. The role of the CTD in regulating Ptc localization was confirmed by monitoring CD2, CD2-CTD, and CD2-1/ 2 CTD in S2 cells. Whereas CD2 was exclusively on the plasma membrane, the presence of either the CTD or $1 / 2 \mathrm{CTD}$ caused the protein to accumulate in intracellular particles (data not shown).

The effect of $\mathrm{Hh}$ on the distribution of $\mathrm{Ptc}^{\mathrm{WT}}$ and $\mathrm{Ptc}^{\Delta 1 / 2 \mathrm{C}}$ was also confirmed by monitoring their localization in S2 cells (Fig. 5A-F). Hh colocalized with both $\mathrm{Ptc}^{\mathrm{WT}}$ and $\mathrm{Ptc}^{\Delta 1 / 2 \mathrm{C}}$, and whereas $\mathrm{Ptc}^{\mathrm{WT}}$ was intracellular in these cells, most $\mathrm{Ptc}^{\Delta 1 / 2 \mathrm{C}}$ was at the cell surface. The proportion of intracellular $\mathrm{Hh}$ was low in $\mathrm{Ptc}^{\Delta 1 / 2 \mathrm{C}}$-expressing cells. As shown in Figure 5G-L, similar assays of $\mathrm{Ptc}^{3 \mathrm{P}}$ and $\mathrm{Ptc}^{\mathrm{PPAA}}$ revealed that these mutant Ptc proteins adopted a distribution that is indistinguishable from $\mathrm{Ptc}^{\mathrm{WT}}$; they colocalized with $\mathrm{Hh}$ in intracellular accumulations.

\section{Ptc multimerization}

To better understand the significance of the trimerization of the CTD, we investigated the oligomerization state of the Ptc protein itself using several different assays. First, FRET assays with transfected S2 cells revealed efficient energy transfer between CFP and YFP derivatives of Ptc (Fig. 6A). FRET of coexpressed CFP-Ptc and YFP-Ptc was of an equivalent magnitude to FRET observed in cells that expressed a CFP-YFP protein fusion. These data suggest that the in vivo association of Ptc monomers with each other is significant. Second, coimmunoprecipitation studies and FRET analysis showed that multimerization did not require the CTD. $\mathrm{Ptc}^{\Delta 1 / 2 \mathrm{C}}$ coimmunoprecipitated with $\mathrm{Ptc}^{\Delta 1 / 2 \mathrm{C}}$ as well as with Ptc ${ }^{\text {WT }}$ (Fig. 6B). FRET was also observed in cells expressing CFP-Ptc ${ }^{\Delta \mathrm{C}}$ and YFP-Ptc ${ }^{\Delta \mathrm{C}}$. These data indicate that the in vivo association of Ptc monomers does not depend upon self-association of the CTD, and suggest that interactions between other segments of the protein are sufficient to form stable multimers. Since contacts between transmembrane helices of AcrB are exten-

Table 2. Yeast two-hybrid assays of CTD ${ }^{W T}$ and CTD PPAA with Nedd4 and the 3WW domain of Nedd4 (residues 234-453)

\begin{tabular}{|c|c|c|c|c|}
\hline & pGAD424 & pGAD424-CTD $^{\text {WT }}$ & pGAD424-Nedd4 & pGAD424-Nedd4 ${ }^{3 \mathrm{wW}}$ \\
\hline pGBT9 & - & - & - & - \\
\hline pGBT9-CTDWT & - & + & + & + \\
\hline PGBT9-CTD ${ }^{\text {PPAA }}$ & - & + & - & - \\
\hline
\end{tabular}

(+) growth on selective medium; (-) poor or no growth. 


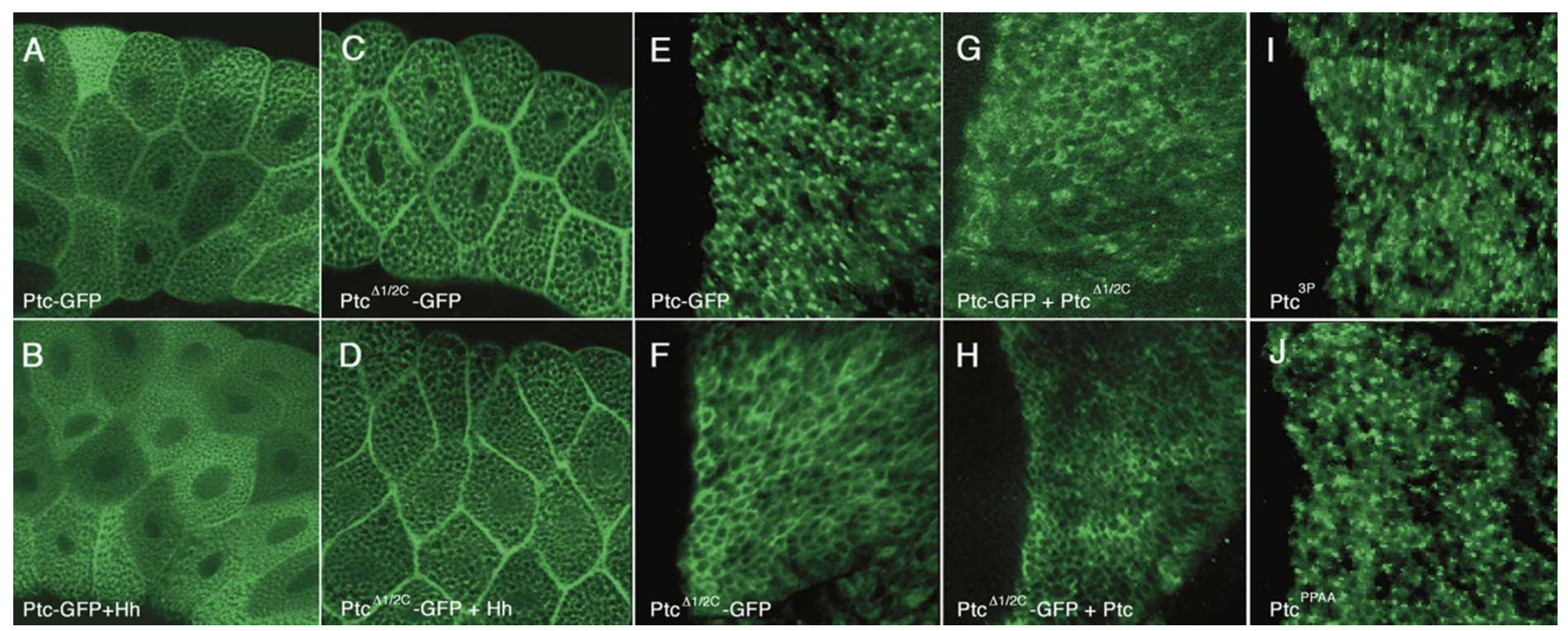

Figure 4. Patched protein redistribution in response to Hh requires the CTD. $(A-D)$ GFP fluorescence in salivary glands expressing Ptc-GFP $(A, B)$ or Ptc ${ }^{\Delta 1 / 2 C}$-GFP $(C, D)$ under control of $S G S$-Gal4 in the presence $(B, D)$ or absence $(A, C)$ of Hh. $(E-H)$ Epi-fluorescence monitored in wing discs expressing GFP-Ptc $(E)$, GFP-Ptc ${ }^{\Delta 1 / 2 C}(F)$, both GFP-Ptc and $\operatorname{Ptc}^{\Delta 1 / 2 C}(G)$, both Ptc and GFP-Ptc ${ }^{\Delta 1 / 2 C}(H)$, Ptc ${ }^{3 \mathrm{P}}$ $(I)$, or Ptc ${ }^{\mathrm{PPAA}}(J)$ in the posterior compartment under control of en-Gal4.

sive and AcrB lacks an extended CTD, the observed multimerization of $\mathrm{Ptc}^{\Delta \mathrm{C}}$ is not unexpected. Third, Western analyses of various Ptc mutants, including $\mathrm{Ptc}^{\mathrm{WT}}, \mathrm{Ptc}^{\Delta 1 / 2 \mathrm{C}}$, and CFP-Ptc, revealed that these Ptc proteins migrated in SDS-PAGE as both monomers and

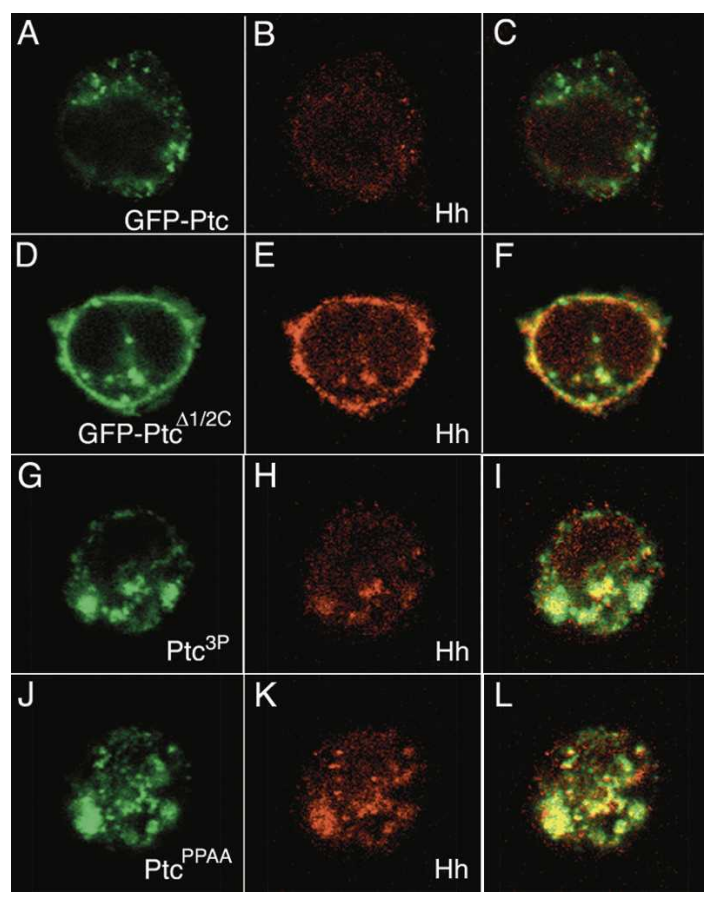

Figure 5. Ptc is a Hh receptor. Distribution of Ptc (green; $A, C$, $D, F, G, I, J, L)$ and Hh-N (red; $B, C, E, F, H, I, K, L)$ in S2 cells expressing GFP-Ptc $(A-C)$, GFP-Ptc ${ }^{\Delta 1 / 2 \mathrm{C}}(D-F), \operatorname{Ptc}^{3 \mathrm{P}}(G-I)$, and Ptc ${ }^{\text {PPAA }}$ $(J-L)$, and exposed to Hh-N conditioned medium. (C,F,I,L) Merged images. Hh was detected with $\alpha$-Hh antibody. Ptc was detected with $\alpha$-Ptc antibody in panels $G, I, I$, and $L$. Images are confocal micrographs. multimers (Fig. 3A,D). Many multimeric membrane proteins do not dissociate in SDS, and although the proportion of Ptc in either monomer or multimer was variable in our experiments, both the monomer or multimer forms electrophoresed as discrete entities. In addition, their migration in the gels correlated with their relative size: Both monomer and multimer forms of $\mathrm{Ptc}^{\Delta \mathrm{C}} \mathrm{mi}-$ grated farther than the Ptc ${ }^{\mathrm{WT}}$ multimer. The sizes of the multimers, as indicated by electrophoretic mobilities, are consistent with a trimer constitution (Fig. 3D), and these mobilities were not changed by treatment with $\lambda$ phosphatase (200 U) or by prior incubation of cells with tunicamycin (at $15 \mu \mathrm{g} / \mathrm{mL}$ ) (data not shown), an inhibitor of N-glycosylation. All of the CTD mutants we characterized were detected as both monomers and trimers, suggesting that the Ptc trimers observed in these SDSPAGE gels formed irrespective of the contribution or apparent influence of the CTD. Together, these data indicate that self-association of the CTD is not required for Ptc oligomerization, although oligomerization of the CTD is required for normal turnover.

Since $\mathrm{Ptc}^{\mathrm{WT}}$ and $\mathrm{Ptc}^{\Delta 1 / 2 \mathrm{C}}$ adopt different intracellular distributions and can interact with each other, we asked if the presence of $\mathrm{Ptc}^{\Delta 1 / 2 \mathrm{C}}$ affects the distribution of $\mathrm{Ptc}^{\mathrm{WT}}$. Histological studies of embryos and imaginal discs reveal that Ptc accumulates in large punctae that may correspond to multivesicular bodies and endosomes in Hh-receiving cells (Capdevila et al. 1994b; Tabata and Kornberg 1994; Strutt et al. 2001). Ptc expressed ectopically in the Hh-producing cells in the P compartment of wing discs also accumulates in punctae (Ramirez-Weber et al. 2000). We examined the distribution of $\mathrm{Ptc}^{\mathrm{WT}}$, $\mathrm{Ptc}^{\Delta 1 / 2 \mathrm{C}}, \mathrm{Ptc}^{3 \mathrm{P}}$, and Ptc ${ }^{\mathrm{PPAA}}$ in wing discs that ectopically express these proteins in P compartment cells (Fig. $4 \mathrm{E}-J)$. GFP-Ptc ${ }^{\Delta 1 / 2 \mathrm{C}}$ had a diffuse, nonnuclear distribution in such disc cells, and did not accumulate in punctae. In contrast, GFP-Ptc ${ }^{\mathrm{WT}}, \mathrm{Ptc}^{3 \mathrm{P}}$, and Ptc ${ }^{\mathrm{PPAA}}$ accumu- 
Lu et al.

A

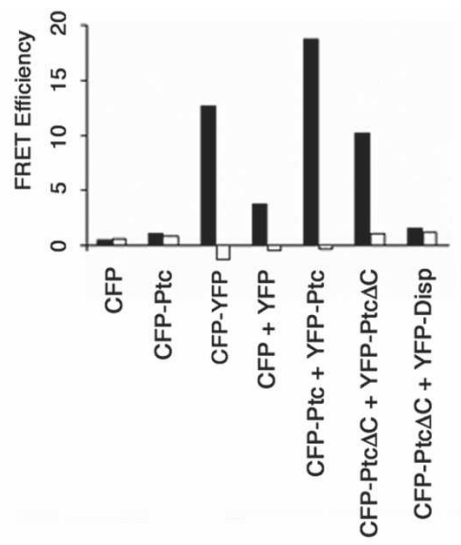

B

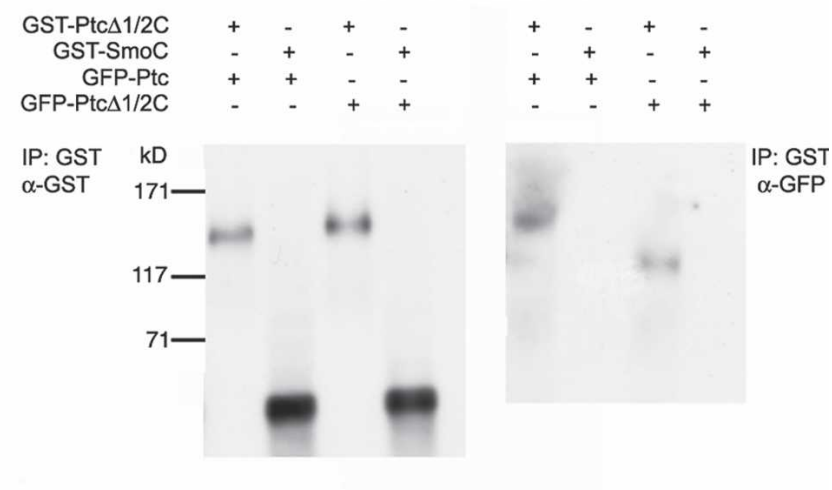

Figure 6. Ptc is a multimer. (A) FRET analysis of S2 cells expressing the indicated proteins (CFP, YFP, a CFP-YFP fusion; a CFP-Ptc or YFP-Ptc fusion; a CFP-Ptc ${ }^{\Delta \mathrm{C}}$ or YFP-Ptc ${ }^{\Delta \mathrm{C}}$ fusion; or a YFP-Disp fusion. (Black bars) Donor FRET from the bleached region; (white bars) donor FRET from unbleached region. (B) Coimmunoprecipitation analysis of S2 cells expressing GFP-Ptc ${ }^{\mathrm{WT}}$, GFP-Ptc ${ }^{\Delta 1 / 2 \mathrm{C}}$, GST-Ptc ${ }^{\Delta 1 / 2 C}$, or GST-SmoC (residues 559-1036), immunoprecipitated with $\alpha$-GST antibody and probed with either $\alpha$-GST (left) or $\alpha$-GFP (right) antibodies.

lated in many brightly fluorescent punctae. Coexpression of GFP-Ptc ${ }^{\Delta 1 / 2 C}$ and $\mathrm{Ptc}^{\mathrm{WT}}$ did not affect the localization of $\mathrm{Ptc}^{\Delta 1 / 2 \mathrm{C}}$, but the distribution of GFP$\mathrm{Ptc}^{\mathrm{WT}}$ changed dramatically in the presence of $\mathrm{Ptc}^{\Delta 1 / 2 \mathrm{C}}$; the number of fluorescent punctae was reduced $>75 \%$. These observations are consistent with the conclusion that $\operatorname{Ptc}^{\Delta 1 / 2 \mathrm{C}}$ can multimerize, and provide evidence for $\mathrm{Ptc}^{\mathrm{WT}}-\mathrm{Ptc}^{\mathrm{\Delta} / 2 \mathrm{C}}$ heterotrimers. These observations also confirm that $\mathrm{Ptc}^{3 \mathrm{P}}$ and $\mathrm{Ptc}^{\mathrm{PPAA}}$, in contrast to $\mathrm{Ptc}^{\Delta 1 / 2 \mathrm{C}}$, accumulated internally in the presence of $\mathrm{Hh}$.

\section{Conservation of CTD functions}

The Ptc proteins have high levels of sequence conservation. Conservation in the 12 transmembrane domains and the two large extracellular loops between mouse and Drosophila Ptc proteins ranges between 50\% and 90\% (Supplementary Fig. 3). In contrast, comparing CTDs of the Drosophila and mouse Ptc proteins identifies only small islands of conservation in these domains that overall have $<30 \%$ sequence identity. To determine if, despite its lower sequence conservation, the CTD of a vertebrate Ptc homolog also regulates turnover, we monitored the stability of mouse Ptc in transfected COS-7 cells. Mouse Ptc was unstable, and was degraded rapidly after protein synthesis was blocked by the addition of cycloheximide. The half-life of the mouse Ptc was $<2 \mathrm{~h}$. In contrast, a C-terminal truncation mutant that lacks most of the CTD was relatively stable, with $>80 \%$ remaining after $3 \mathrm{~h}$ of incubation (Fig. 3C). These results are consistent with several previous reports of enhanced Shh binding to cells that express C-terminally truncated mouse Ptc (Stone et al. 1996; Fuse et al. 1999). To determine if the mouse CTD can destabilize a heterologous protein, we expressed two forms of the Drosophila Ptc protein in COS-7 cells. Ptc ${ }^{\Delta \mathrm{C}}$ was stable, with $>60 \%$ remaining $6 \mathrm{~h}$ after addition of cycloheximide. However, $\mathrm{Ptc}^{\Delta \mathrm{C}-\mathrm{mCTD}}$, a protein consisting of the mouse CTD (residues 1162-1434) fused to the C terminus of $\mathrm{Ptc}^{\Delta \mathrm{C}}$ (residues 1-1117), was less stable, with $\sim 20 \%$ remaining $6 \mathrm{~h}$ after addition of cycloheximide. These results indicate that the mouse CTD, like the Drosophila CTD, functions to enhance protein turnover. Indeed, the relative stability/instability of protein with or without a mouse Ptc CTD was similar to the Drosophila Ptc with or without a Drosophila CTD in S2 cells.

We tested whether the mouse CTD conferred instability to $\mathrm{Ptc}^{\Delta \mathrm{C}}$ in Drosophila S2 cells, but observed that it did not. The half-life of $\operatorname{Ptc}^{\Delta C}$ and Ptc ${ }^{\Delta C-m C T D}$ was indistinguishable (data not shown). These results suggest that the functionality of the Drosophila and mouse CTDs to regulate turnover has been conserved, but they do not reveal the extent to which the mechanism that recognizes and processes the CTDs has also been conserved.

\section{Discussion}

This study improves our understanding of the Ptc protein in several ways. It revealed that Ptc is a multimer, a finding that has implications for the role of Ptc as a regulator of Hh signal transduction. It also identified three distinct activities of the CTD. The CTD regulates Ptc degradation: Ptc is stabilized by mutations that alter the CTD. The CTD regulates Ptc trafficking: In contrast to the wild-type Ptc, which concentrates in internal locations in the presence of $\mathrm{Hh}$, Ptc lacking a CTD localizes predominantly at the cell surface. Lastly, the CTD trimerizes and contains a Nedd4 recognition motif. We discuss below the implications of these findings for the mechanism of Ptc function.

\section{Ptc is a multimeric Hh receptor}

It bears noting that prior to this study, evidence that Drosophila Ptc is a Hh receptor had been limited to genetic studies that demonstrated that Ptc functions up- 
stream of all Hh pathway components in Hh-receiving cells (Ingham et al. 1991; Sampedro and Guerrero 1991; Chen and Struhl 1996). Many previous attempts in this laboratory to observe $\mathrm{Hh}$ binding at the surface of Drosophila cells did not succeed (D. Casso and T.B. Kornberg, unpubl.), and the abundant internal accumulation of $\mathrm{Hh}$ in cells that ectopically express Ptc ${ }^{\mathrm{WT}}$ (Fig. 5A,C) fairly represents the results we obtained. Hh could be shown to colocalize with Ptc in S2, disc, and embryo cells, but not at the cell surface. In contrast, the presence of both $\mathrm{Hh}$ and $\mathrm{Ptc}^{\Delta 1 / 2 \mathrm{C}}$ at the surface of $\mathrm{Ptc}^{\Delta 1 / 2 \mathrm{C}}$-expressing cells suggests that $\mathrm{Ptc}^{\Delta 1 / 2 \mathrm{C}}$ binds $\mathrm{Hh}$ directly. Results we obtained that are consistent with this proposal include the suppression of $\mathrm{Hh}$ signaling in discs that express $\mathrm{Ptc}^{\Delta 1 / 2 \mathrm{C}}$ (Fig. 2; Johnson et al. 2000), a presumed consequence of $\mathrm{Ptc}^{\Delta 1 / 2 \mathrm{C}}$ reducing the effective concentration of $\mathrm{Hh}$ by binding to and sequestering $\mathrm{Hh}$. In addition, the failure of $\mathrm{Ptc}^{\Delta 1 / 2 \mathrm{C}}$ to redistribute internally in salivary gland cells in the presence of Hh (Fig. 4D) showed that protein lacking a CTD does not internalize efficiently. In contrast, internalization of $\mathrm{Ptc}^{\mathrm{WT}}$ is apparently very efficient. Further studies to characterize the interaction between Ptc and Hh are in progress.

As noted in the Introduction, complementation between Ptc alleles (Johnson et al. 2000; Mullor and Guerrero 2000; Martin et al. 2001; Vegh and Basler 2003; Torroja et al. 2004) and sequence similarity to multimeric RND transporters (Nikaido and Zgurskaya 2001) led others to propose that Ptc is a multimer (Johnson et al. 2000; Mullor and Guerrero 2000; Martin et al. 2001; Vegh and Basler 2003; Casali and Struhl 2004; Torroja et al. 2004). Our study supports this model in several ways. We obtained evidence for direct interaction between Ptc monomers by FRET (Fig. 6A). We identified a stable form of Ptc that migrated in SDS-PAGE at the molecular weight expected of a Ptc trimer (Fig. 3A,D). Although we did not determine the subunit composition of this high-molecular-weight form, the fact that the CTD is a stable trimer in solution supports the proposition that this isomer of Ptc is a homotrimer. We also obtained functional evidence for Ptc self-association. We observed that Ptc ${ }^{\Delta 1 / 2 C}$ changed the distribution of $\mathrm{Ptc}^{\mathrm{WT}}$ when the two proteins were expressed together in cells of the wing disc posterior compartment (Fig. 4G). In addition, expression of $\mathrm{Ptc}^{\Delta 1 / 2 \mathrm{C}}$ in the anterior compartment activated $\mathrm{Hh}$ signaling even in regions that receive little or no Hh (Fig. $2 F)$. Since the $\mathrm{Hh}$ pathway is activated in a ligand-independent manner in the absence of ptc function (RamirezWeber et al. 2000; for review, see Ingham 1998), we suggest that together these findings indicate that Ptc is a trimer, that Ptc can form heterotrimers that contain both wild-type and CTD-mutant subunits, and that such heterotrimers lack the capacity to repress the Hh pathway.

Our results do not imply that trimerization of Ptc requires the CTD or that trimerization of the CTD is regulated. Since Ptc protein that lacks a CTD can form multimers (Fig. 3A,D) and can inhibit Ptc ${ }^{\mathrm{WT}}$ (Fig. 2F), the CTD is apparently not required for Ptc to associate with itself. It may be relevant that its ancestral relative, AcrB,
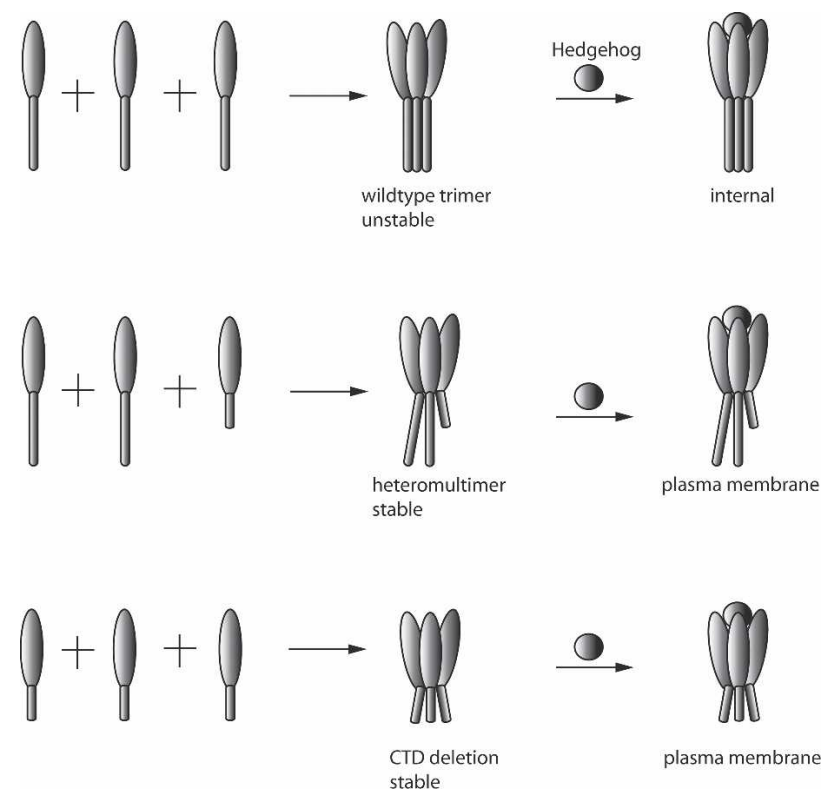

Figure 7. Model of Ptc homo- and heteromultimers. Ptc monomers can multimerize to form stable trimers that repress the Hh signaling pathway, unless bound by Hh. Ptc monomers with a mutant CTD can form stable trimers that consist entirely of the mutant protein or include wild-type Ptc. Trimers containing CTD mutations can bind $\mathrm{Hh}$, are stable, but are incapable of inactivating the Hh signaling pathway.

has no cytoplasmic residues C-terminal to its 12 th transmembrane domain, so it clearly has no requirement for a CTD to form a stable trimer (Murakami et al. 2002). Figure 7 summarizes our proposed model of the Ptc structure, depicting the wild-type protein, the hypothetical heteromultimer, and the homotrimer of a protein lacking a CTD.

The nature of the activity that Ptc contributes to regulate the Hh pathway is not known. Corcoran and Scott (2006) recently reported that the vertebrate $\mathrm{Hh}$ pathway is activated by and is dependent on oxysterols, and these authors proposed that Ptc might function as a pump to control the sterol levels that regulate Smo activity. Although this model is attractive, our understanding of Ptc has been too rudimentary to test for such activities directly. Nevertheless, if Ptc is structurally homologous with the family of RND transporters as its sequence, presumed topology and apparent trimer form suggests, then our findings support the possibility that Ptc also shares functionality with this ancestral transporter family.

\section{Functions of the CTD}

Analysis of CTD mutants revealed that the CTD controls Ptc localization and half-life. Both functions mapped to the CTD's 106 C-terminal residues. Deletion of this CTD reduced the levels of internal Ptc and stabilized the protein. Note that assays of Ptc localization measured its steady-state distribution and did not distinguish between effects on the rate of internalization or on 
recycling of internalized protein to the cell surface. Therefore, we do not know whether Hh directly affects the removal of Ptc from the cell surface, or if it affects a process that sorts internalized protein. Since internalized Ptc ${ }^{\mathrm{WT}}$ has been observed to colocalize with $\mathrm{Hh}$ in multivesicular bodies (Capdevila et al. 1994b), which are late endosomes that ferry cargo to lysosomes, it seems reasonable to propose that internalized $\mathrm{Hh}$-bound Ptc is programmed for degradation, and that internalization is a requisite step in the pathway toward that fate. Our observation that the instability conferred by the CTD is sensitive to $\mathrm{NH}_{4} \mathrm{Cl}$, an inhibitor of lysosomal proteolysis (Fig. 3E), is consistent with this model. These experiments do not reveal whether unbound Ptc cycles between early endosomes and the cell surface in the absence of $\mathrm{Hh}$, and so these experiments do not implicate $\mathrm{Hh}$ in the regulation of Ptc endocytosis per se.

The phenotypes of the $p t c^{3 P}$ and $p t c^{P P A A}$ missense mutants add to our understanding of the Ptc degradation pathway. Both the $\mathrm{Ptc}^{3 \mathrm{P}}$ and the Ptc ${ }^{\mathrm{PPAA}}$ mutant proteins are processed by the degradation pathway less efficiently than $\mathrm{Ptc}^{\mathrm{WT}}$. Yet, both $\mathrm{Ptc}^{3 \mathrm{P}}$ and $\mathrm{Ptc}^{\mathrm{PPAA}}$ internalize in the presence of $\mathrm{Hh}$ (Fig. 5G-L). Since Ptc ${ }^{\text {PPAA }}$ mutates a PPXY motif in the CTD that is a recognition site for Nedd4, these results suggest that mono-ubiquitination in the CTD is a signal that targets Ptc to lysosomes, but mono-ubiquitination is not required for movement to early endosomes. Ptc ${ }^{3 \mathrm{P}}$ retains the PPXY motif, but in contrast to CTD ${ }^{\mathrm{WT}}$ and $\mathrm{CTD}^{\mathrm{PPAA}}$, its CTD cannot multimerize (Table 2). This behavior suggests that the process that marks Ptc for sorting to late endosomes may require both the PPXY motif and a conformation that is generated by the trimerized CTD. Since both $\mathrm{Ptc}^{3 \mathrm{P}}$ and the $\mathrm{Ptc}^{\mathrm{PPAA}}$ proteins can sequester $\mathrm{Hh}$, and both internalize and colocalize with $\mathrm{Hh}$, these functions are apparently required for sorting, not for $\mathrm{Hh}$ binding or internalization. The inability of $\mathrm{Ptc}^{\Delta 1 / 2 \mathrm{C}}$ to internalize indicates that the $106 \mathrm{C}$-terminal residues also include a domain that targets Ptc to early endosomes.

The importance of regulated turnover to the proper function of signaling pathways has recently been illuminated by the isolation and analysis of the Drosophila vps25 and erupted genes (Moberg et al. 2005; Thompson et al. 2005; Vaccari and Bilder 2005; Herz et al. 2006). Both genes encode proteins that function in endosomal sorting, and mutants have impressive phenotypes characterized by unregulated growth and defective patterning. Endocytic defects in mutant clones result in accumulation of signaling receptors such as Notch and Thickveins as well as other signaling components, highlighting the critical role that endocytic sorting plays in regulating signaling. The multiple functions of the Ptc CTD that are necessary for proper trafficking and turnover testify to the many steps in this complex process.

\section{Conservation of CTD function in Drosophila and mouse Ptc proteins}

Cells that express a mouse Ptc CTD deletion (Ptc ${ }^{\Delta C T D}$ ) have more than five times the number of binding sites for Shh as do cells expressing wild-type Ptc (Fuse et al. 1999). These authors did not explore the basis for the increased binding capacity of $\mathrm{Ptc}^{\Delta \mathrm{CTD}}$-expressing cells, but our analysis has now revealed that the mouse Ptc $^{\Delta C T D}$ mutant protein, like the Drosophila Ptc ${ }^{\Delta C T D}$, has an increased half-life. We note that both mouse and human Ptc have a PPXY motif in their respective CTDs at a location that is comparable to that of the Drosophila PPAY sequence. Although we have not investigated the role of the PPXY motif in mouse Ptc, it seems reasonable to propose that the functions of the CTD are generally conserved in the vertebrate and invertebrate proteins, that the increased stability of mouse $\mathrm{Ptc}^{\Delta \mathrm{CTD}}$ derives in part from the absence of the PPXY sequence, that mouse $\mathrm{Ptc}^{\triangle \mathrm{CTD}}$ is not internalized efficiently, and that these properties contribute to the increased binding of Shh to $\mathrm{Ptc}^{\triangle \mathrm{CTD}}$-expressing cells.

\section{Materials and methods}

\section{Plasmid construction}

For the yeast two-hybrid assays, the Drosophila ptc cDNA encoding 1104-1286 (CTD), 1104-1180 (N-1/2CTD), 1181-1286 (C-1/2CTD), and CTD containing three missense mutations T1260P, T1263P, and T1265P (3PCTD) were cloned into pGBT9 (BD Biosciences) and pGAD424 (BD Biosciences). GFP-Ptc fusion proteins placed GFP at the $\mathrm{N}$ terminus. pCITE-4a was used for in vitro translation. pGEX4T-1 (Amersham Biosciences), pAC5.1 (Invitrogen), pcDNA3.1 (Invitrogen), pUAST (Brand and Perrimon 1993), and pET28-HMT (which encodes a $\mathrm{His}_{6}$-tagged MBP fusion and includes a cleavage site for the Tobacco Etch Virus protease [TEV]) were used for in vitro or in vivo gene expression.

\section{Yeast two-hybrid screening}

Yeast two-hybrid screening was performed as described (Bai and Elledge 1997). Briefly, pGBT9-PtcCTD plasmid was used as bait to screen a Drosophila early embryo cDNA library cloned into a pACT2 vector (generously provided by S. Elledge). Yeast PJ694A cells were transformed sequentially with the bait construct and the cDNA library using the lithium acetate/single-stranded carrier DNA/polyethylene glycol method (Gietz and Woods 2002). Cells were plated on SD-HIS-LEU-ADE-TRP (-HLAT) medium (BIO 101 Systems, Qbiogene). Positive clones were tested for $\beta$-galactosidase activity, and selected plasmids were sequenced.

\section{Salivary gland preparation and embryo rescue assays}

For salivary gland preparations, UAS-GFP-ptc $c^{1 / 2 C}, U A S-G F P$ $p t c$, and UAS-hhN stocks were expressed with SGS-GAL4. Third instar larval salivary glands were dissected and mounted for confocal microscopy. For rescue experiments, $p t c^{B 98}$; UAS$p t c / H S$-GAL4 embryos and $p t c^{B 98} ; U A S-p t c^{\Delta 1 / 2 C} / H S-G A L 4 \mathrm{em}-$ bryos were collected and aged for $40 \mathrm{~h}$ at $18^{\circ} \mathrm{C}$ and cuticles were prepared as described previously (Ramirez-Weber et al. 2000).

\section{Cell culture and drug treatment}

Cos-7 cells were cultured with Dulbecco's Modified Eagle Medium containing $10 \%(\mathrm{v} / \mathrm{v})$ fetal calf serum; cells were incubated at $37^{\circ} \mathrm{C}, 5 \% \mathrm{CO}_{2}$. S2 cells were maintained in Shields and Sang M3 insect medium (Sigma). Transient transfection was 
performed using Effectene (Qiagen). Conditioned medium was collected from HhN-S2 or control S2 cells. Transfected S2 cells were treated with $\mathrm{HhN}$-containing or control medium for $3 \mathrm{~h}$ Cycloheximide treatment was for the indicated times at a final concentration of $100 \mu \mathrm{M}$. $\mathrm{NH}_{4} \mathrm{Cl}$ treatment was at $50 \mathrm{mM}$ for 3 $\mathrm{h}$. Levels of protein were determined by scanning autoradiographs of Western blots with a densitometer. Quantification using a Storm PhosphorImager gave equivalent results.

For the pulse-chase analysis of Ptc turnover, transfected S2 cells were cultured in $10-\mathrm{cm}$ dishes at $3.0 \times 10^{7}$ cells per dish for $24 \mathrm{~h}$ and washed three times before incubation in $\mathrm{Met}^{-} \mathrm{Grace}^{\prime} \mathrm{s}$ medium for $2 \mathrm{~h}$. Cells were labeled with $200 \mu \mathrm{Ci}{ }^{35} \mathrm{~S}$-methionine for $3 \mathrm{~h}$, then washed with PBS, and incubated for the indicated periods in standard M3 medium. After each chase period, the cells were lysed and immunoprecipitated with glutathione sepharose 4B. Recovered GST-tagged proteins were fractioned and monitored by autoradiography and with a PhosphorImager.

\section{GST pull-down assays}

GST pull-down experiments were performed as described (Tallec et al. 2003). BL21-gold (DE3) E. coli bacteria (Stratagene) were transformed with pGEX vectors that contained constructs encoding chimeric GST proteins. In vitro translated proteins were synthesized using the TnT-T7 Quick Coupled Transcription/Translation kit (Promega) in the presence of ${ }^{35} \mathrm{~S}$-methionine, and were added to immobilized GST fused proteins. Following incubation of $1 \mathrm{~h}$ at $4^{\circ} \mathrm{C}$ and washes with HKEN buffer (25 mM HEPES at $\mathrm{pH} 7.9,60 \mathrm{mM} \mathrm{KCl}, 1 \mathrm{mM}$ EDTA, $0.5 \%$ NP40, 1 mM DTT, 1 mM PMSF, $5 \mu \mathrm{g} / \mathrm{mL}$ Leupeptin), interacting proteins were eluted in $5 \times$ Laemmli loading buffer, boiled, separated on $12 \%$ acrylamide SDS-PAGE, and autoradiographed.

\section{Immunoprecipitations and Western blots}

Drosophila S2 cells were transiently cotransfected with a pAcGAL4 plasmid and with UAS constructs to produce the indicated chimeric proteins. Cells were lysed in NETN (100 mM $\mathrm{NaCl}, 20 \mathrm{mM}$ Tris at $\mathrm{pH} 8.0,1 \mathrm{mM}$ EDTA, $0.2 \%$ NP40) with a protease-inhibitor cocktail (Invitrogen). To precipitate the complexes, supernatants were incubated $4 \mathrm{~h}$ with glutathione sepharose $4 \mathrm{~B}$ gel (Pharmacia Biotech). The beads were washed five times with NETN, boiled in $2 \times$ Laemmli sample buffer, and fractionated by SDS-PAGE. Western blot experiments were developed using mouse $\alpha$-Myc antibody (9E10, Santa Cruz Biotechnology) or anti-GST (1/1000). Mouse secondary antibodies were coupled to peroxidase and signals were detected by ECL Plus Western Blotting Detection System (Amersham Biosciences). Western analysis of full-length Ptc or of Ptc mutant proteins was carried out on cell extracts that were prepared after lysis in NETN, the addition of $2 \times$ Laemmli sample buffer, and gel electrophoresis (without boiling). Blots were quantified by densitometry using an Alpha Innotech Fluorchem 5500 densitometer.

\section{Real-time PCR}

Total RNA from wing disc cells was isolated by Trizol extraction (Invitrogen). One microgram of total RNA was treated with DNase I and random primed cDNA was prepared from total RNA with 200 U of RT using the SuperScript II kit (Invitrogen). Real-time PCR was carried out on an ABI 7700 Sequence Detector using the qPCR Mastermix Plus for Sybr TM Green I (Eurogentec). PCR were performed with $50 \mathrm{ng}$ of cDNA in the presence of $2.5 \mathrm{mM} \mathrm{MgCl}_{2}, 200 \mu \mathrm{M}$ deoxynucleoside triphos- phates (dNTPs), 1.25 U Hot Goldstar DNA polymerase, and 300 $\mathrm{nM}$ specific primers. Reaction parameters were $10 \mathrm{~min}$ at $95^{\circ} \mathrm{C}$ followed by 40 cycles at $95^{\circ} \mathrm{C}(15 \mathrm{sec})$, and $60^{\circ} \mathrm{C}(1 \mathrm{~min})$.

\section{Protein expression and purification}

Cells containing the MBP expression plasmids /derivatives of pET28-HMT, see above) were grown to $\mathrm{OD}_{600} 0.6-0.8$ in $100 \mathrm{~mL}$ of rich glucose broth and induced with IPTG $(0.4 \mathrm{mM})$ for 3-6 h Cells were harvested and frozen at $-20^{\circ} \mathrm{C}$, thawed, resuspended in $50 \mathrm{~mL}$ lysis buffer (100 mM Tris at pH 7.6, $200 \mathrm{mM} \mathrm{KCl,} \mathrm{10 \%}$ sucrose, $20 \mu \mathrm{g} / \mathrm{mL}$ lysozyme, $25 \mu \mathrm{g} / \mathrm{mL}$ DNaseI, $5 \mathrm{mM} \mathrm{MgCl}_{2}$, 1 Complete protease inhibitor tablet; Roche), and sonicated for $3 \mathrm{~min}$. After centrifuging the cell lysate at $27,000 \times \mathrm{g}$ for $30 \mathrm{~min}$, the supernatant was passed through a 0.45 - $\mu \mathrm{m}$ syringe filter and injected onto a 10-mL Ni-charged column equilibrated with wash buffer (10 mM HEPES at pH 7.3, $250 \mathrm{mM} \mathrm{KCl,} 1 \mathrm{mM}$ PMSF). MBP fusions were eluted with imidazole buffer $(10 \mathrm{mM}$ HEPES at $\mathrm{pH} 7.3,250 \mathrm{mM} \mathrm{KCl}, 200 \mathrm{mM}$ imidazole) over four column volumes at a flow rate of $8 \mathrm{~mL} / \mathrm{min}$. The column effluent was monitored by UV absorbance at $280 \mathrm{~nm}$. Peak fractions were loaded onto a 10-mL Amylose column (New England Biolabs) equilibrated with wash buffer. MBP fusions were eluted in $100 \%$ maltose buffer (10 mM HEPES at pH 7.3, $250 \mathrm{mM} \mathrm{KCl}, 10$ $\mathrm{mM}$ maltose) over two column volumes at a flow rate of 2.5 $\mathrm{mL} / \mathrm{min}$. The eluant was monitored by SDS-PAGE and peak fractions were pooled and concentrated to $1 \mathrm{~mL}$ (Centricon). Purified MBP fusion protein was subjected to Superdex 200 FPLC chromatography (Amersham Biosciences) in washing buffer (10 mM HEPES at $\mathrm{pH} 7.3,250 \mathrm{mM} \mathrm{KCl}, 1 \mathrm{mM}$ EDTA) at a flow rate of $0.5 \mathrm{~mL} / \mathrm{min}$. The molecular weights of the peak fractions were estimated by comparison to standards (Ferritin, Aldolase, Albumin, Ovalbumin, Chymotrypsinogin A, RNase A) that were chromatographed separately.

\section{FRET analysis}

FRET analysis was by the method of Karpova et al. (2003), using a Zeiss LSM510 confocal microscope operating with a $40-\mathrm{mW}$ argon laser tuned to 458,488 , and $514 \mathrm{~nm}$. Cells were examined with a $63 \times 1.3$ NA Zeiss oil immersion objective. FRET was measured using the acceptor photobleaching method (Kenworthy 2001). In our acceptor photobleaching protocol, five CFP images were collected at 10 -sec intervals for a designated region that was then bleached in the YFP channel by scanning 20 times using the 514 argon laser line at $75 \%$ intensity $(95-\mu \mathrm{W}$ laser power at the specimen). After bleaching, five additional CFP images were collected and the increase in CFP fluorescence was monitored. Maximum increase of CFP fluorescence was detected in the first post-bleach image (image \#6). To calculate the FRET efficiency $\left(E_{\mathrm{F}}\right)$, we used the formula $E_{\mathrm{F}}=\left(I_{6}-I_{5}\right) \times 100 / I_{6}$, where $I_{n}$ is the CFP intensity at the $n$th time point. As a control, similar calculations were made for nonbleached regions of the specimen that were imaged at the same intervals: $C_{\mathrm{F}}=\left|I_{6}-I_{5}\right|$ $\times 100 / I_{6}$. Constructs were N-terminal fusions to CFP and YFP.

\section{Acknowledgments}

We thank Dave Casso, Pao-Tien Chuang, Steve Elledge, Jane W. Gordon, Kevin Hill, Jie Hu, Ya-Jun Li, Yonghai Li, Mingxiang Liao, Dan Minor, Matt Scott, and Yinghui Song for advice, help with procedures, materials, and support. This work was supported by a grant from the NIH to T.B.K.

\section{References}

Alcedo, J., Ayzenzon, M., Von Ohlen, T., Noll, M., and Hooper, J.E. 1996. The Drosophila smoothened gene encodes a seven- 
pass membrane protein, a putative receptor for the hedgehog signal. Cell 86: 221-232.

Altschul, S.F., Gish, W., Miller, W., Myers, E.W., and Lipman, D.J. 1990. Basic local alignment search tool. J. Mol. Biol. 215: 403-410.

Bai, C. and Elledge, S.J. 1997. Gene identification using the yeast two-hybrid system. Methods Enzymol. 283: 141-156.

Bellaiche, Y., The, I., and Perrimon, N. 1998. Tout-velu is a Drosophila homologue of the putative tumour suppressor EXT-1 and is needed for Hh diffusion. Nature 394: 85-88.

Brand, A.H. and Perrimon, N. 1993. Targeted gene expression as a means of altering cell fates and generating dominant phenotypes. Development 118: 401-415.

Burke, R., Nellen, D., Bellotto, M., Hafen, E., Senti, K.A., Dickson, B.J., and Basler, K. 1999. Dispatched, a novel sterolsensing domain protein dedicated to the release of cholesterol-modified hedgehog from signaling cells. Cell 99: 803815.

Capdevila, J., Estrada, M.P., Sanchez-Herrero, E., and Guerrero, I. 1994a. The Drosophila segment polarity gene patched interacts with decapentaplegic in wing development. EMBO J. 13: 71-82.

Capdevila, J., Pariente, F., Sampedro, J., Alonso, J.L., and Guerrero, I. 1994b. Subcellular localization of the segment polarity protein patched suggests an interaction with the wingless reception complex in Drosophila embryos. Development 120: 987-998.

Carstea, E.D., Morris, J.A., Coleman, K.G., Loftus, S.K., Zhang, D., Cummings, C., Gu, J., Rosenfeld, M.A., Pavan, W.J., Krizman, D.B., et al. 1997. Niemann-Pick C1 disease gene: Homology to mediators of cholesterol homeostasis. Science 277: 228-231.

Casali, A. and Struhl, G. 2004. Reading the Hedgehog morphogen gradient by measuring the ratio of bound to unbound Patched protein. Nature 431: 76-80.

Chen, Y. and Struhl, G. 1996. Dual roles for patched in sequestering and transducing Hedgehog. Cell 87: 553-563.

Corcoran, R.B. and Scott, M.P. 2006. Oxysterols stimulate Sonic hedgehog signal transduction and proliferation of medulloblastoma cells. Proc. Natl. Acad. Sci. 103: 8408-8413.

Denef, N., Neubuser, D., Perez, L., and Cohen, S.M. 2000. Hedgehog induces opposite changes in turnover and subcellular localization of patched and smoothened. Cell 102: $521-$ 531.

Formstecher, E., Aresta, S., Collura, V., Hamburger, A., Meil, A., Trehin, A., Reverdy, C., Betin, V., Maire, S., Brun, C., et al. 2005. Protein interaction mapping: A Drosophila case study. Genome Res. 15: 376-384.

Fuse, N., Maiti, T., Wang, B., Porter, J.A., Hall, T.M., Leahy, D.J., and Beachy, P.A. 1999. Sonic hedgehog protein signals not as a hydrolytic enzyme but as an apparent ligand for patched. Proc. Natl. Acad. Sci. 96: 10992-10999.

Gietz, R.D. and Woods, R.A. 2002. Transformation of yeast by lithium acetate/single-stranded carrier DNA/polyethylene glycol method. Methods Enzymol. 350: 87-96.

Goodrich, L.V., Johnson, R.L., Milenkovic, L., McMahon, J.A., and Scott, M.P. 1996. Conservation of the hedgehog/patched signaling pathway from flies to mice: Induction of a mouse patched gene by Hedgehog. Genes \& Dev. 10: 301-312.

Herz, H.M., Chen, Z., Scherr, H., Lackey, M., Bolduc, C., and Bergmann, A. 2006. vps 25 mosaics display non-autonomous cell survival and overgrowth, and autonomous apoptosis. Development 133: 1871-1880.

Hicke, L. and Dunn, R. 2003. Regulation of membrane protein transport by ubiquitin and ubiquitin-binding proteins. Annu. Rev. Cell Dev. Biol. 19: 141-172.
Hime, G.R., Lada, H., Fietz, M.J., Gillies, S., Passmore, A., Wicking, C., and Wainwright, B.J. 2004. Functional analysis in Drosophila indicates that the NBCCS/PTCH1 mutation G509V results in activation of smoothened through a dominant-negative mechanism. Dev. Dyn. 229: 780-790.

Ingham, P.W. 1993. Localized hedgehog activity controls spatial limits of wingless transcription in the Drosophila embryo. Nature 366: 560-562.

. 1998. Transducing Hedgehog: The story so far. EMBO $J$. 17: 3505-3511.

Ingham, P.W. and Fietz, M.J. 1995. Quantitative effects of hedgehog and decapentaplegic activity on the patterning of the Drosophila wing. Curr. Biol. 5: 432-440.

Ingham, P.W., Taylor, A.M., and Nakano, Y. 1991. Role of the Drosophila patched gene in positional signalling. Nature 353: $184-187$.

Johnson, R.L., Milenkovic, L., and Scott, M.P. 2000. In vivo functions of the patched protein: Requirement of the $\mathrm{C}$ terminus for target gene inactivation but not Hedgehog sequestration. Mol. Cell 6: 467-478.

Kenworthy, A.K. 2001. Imaging protein-protein interactions using fluorescence resonance energy transfer microscopy. Methods 24: 289-296.

Karpova, T.S., Baumann, C.T., He, L., Wu X., Grammer, A., Lipsky, P., Hager, G.L., and McNally, J.G. 2003. Fluorescence resonance energy transfer from cyan to yellow fluorescent protein detected by acceptor photobleaching using confocal microscopy and a single laser. J. Microsc. 209: $56-$ 70.

Kwok, J.C. and Richardson, D.R. 2004. Examination of the mechanism(s) involved in doxorubicin-mediated iron accumulation in ferritin: Studies using metabolic inhibitors, protein synthesis inhibitors, and lysosomotropic agents. Mol. Pharmacol. 65: 181-195.

Loftus, S.K., Morris, J.A., Carstea, E.D., Gu, J.Z., Cummings, C., Brown, A., Ellison, J., Ohno, K., Rosenfeld, M.A., Tagle, D.A., et al. 1997. Murine model of Niemann-Pick C disease: Mutation in a cholesterol homeostasis gene. Science 277: 232-235.

Marigo, V., Davey, R.A., Zuo, Y., Cunningham, J.M., and Tabin, C.J. 1996. Biochemical evidence that patched is the Hedgehog receptor. Nature 384: 176-179.

Martin, V., Carrillo, G., Torroja, C., and Guerrero, I. 2001. The sterol-sensing domain of Patched protein seems to control Smoothened activity through Patched vesicular trafficking. Curr. Biol. 11: 601-607.

Moberg, K.H., Schelble, S., Burdick, S.K., and Hariharan, I.K. 2005. Mutations in erupted, the Drosophila ortholog of mammalian tumor susceptibility gene 101, elicit non-cellautonomous overgrowth. Dev. Cell 9: 699-710.

Mullor, J.L. and Guerrero, I. 2000. A gain-of-function mutant of patched dissects different responses to the hedgehog gradient. Dev. Biol. 228: 211-224.

Murakami, S., Nakashima, R., Yamashita, E., and Yamaguchi, A. 2002. Crystal structure of bacterial multidrug efflux transporter AcrB. Nature 419: 587-593.

Nakano, Y., Nystedt, S., Shivdasani, A.A., Strutt, H., Thomas, C., and Ingham, P.W. 2004. Functional domains and subcellular distribution of the Hedgehog transducing protein Smoothened in Drosophila. Mech. Dev. 121: 507-518.

Nikaido, H. and Zgurskaya, H.I. 2001. AcrAB and related multidrug efflux pumps of Escherichia coli. J. Mol. Microbiol. Biotechnol. 3: 215-218.

Ostberg, T., Jacobsson, M., Attersand, A., Mata de Urquiza, A., and Jendeberg, L. 2003. A triple mutant of the Drosophila ERR confers ligand-induced suppression of activity. Bio- 
chemistry 42: 6427-6435.

Ramirez-Weber, F.A., Casso, D.J., Aza-Blanc, P., Tabata, T., and Kornberg, T.B. 2000. Hedgehog signal transduction in the posterior compartment of the Drosophila wing imaginal disc. Mol. Cell 6: 479-485.

Rogers, S., Wells, R., and Rechsteiner, M. 1986. Amino acid sequences common to rapidly degraded proteins: The PEST hypothesis. Science 234: 364-368.

Sampedro, J. and Guerrero, I. 1991. Unrestricted expression of the Drosophila gene patched allows a normal segment polarity. Nature 353: 187-190.

Stone, D.M., Hynes, M., Armanini, M., Swanson, T.A., Gu, Q., Johnson, R.L., Scott, M.P., Pennica, D., Goddard, A., Phillips, H., et al. 1996. The tumour-suppressor gene patched encodes a candidate receptor for Sonic hedgehog. Nature 384: 129-134.

Strutt, H., Thomas, C., Nakano, Y., Stark, D., Neave, B., Taylor, A.M., and Ingham, P.W. 2001. Mutations in the sterol-sensing domain of Patched suggest a role for vesicular trafficking in Smoothened regulation. Curr. Biol. 11: 608-613.

Tabata, T. and Kornberg, T.B. 1994. Hedgehog is a signaling protein with a key role in patterning Drosophila imaginal discs. Cell 76: 89-102.

Taipale, J., Cooper, M.K., Maiti, T., and Beachy, P.A. 2002. Patched acts catalytically to suppress the activity of Smoothened. Nature 418: 892-897.

Tallec, L.P., Kirsh, O., Lecomte, M.C., Viengchareun, S., Zennaro, M.C., Dejean, A., and Lombes, M. 2003. Protein inhibitor of activated signal transducer and activator of transcription 1 interacts with the $\mathrm{N}$-terminal domain of mineralocorticoid receptor and represses its transcriptional activity: Implication of small ubiquitin-related modifier 1 modification. Mol. Endocrinol. 17: 2529-2542.

Thompson, B.J., Mathieu, J., Sung, H.H., Loeser, E., Rorth, P., and Cohen, S.M. 2005. Tumor suppressor properties of the ESCRT-II complex component Vps25 in Drosophila. Dev. Cell 9: 711-720.

Torroja, C., Gorfinkiel, N., and Guerrero, I. 2004. Patched controls the Hedgehog gradient by endocytosis in a dynamindependent manner, but this internalization does not play a major role in signal transduction. Development 131: 23952408.

Tseng, T.T., Gratwick, K.S., Kollman, J., Park, D., Nies, D.H., Goffeau, A., and Saier Jr., M.H. 1999. The RND permease superfamily: An ancient, ubiquitous and diverse family that includes human disease and development proteins. J. Mol. Microbiol. Biotechnol. 1: 107-125.

Vaccari, T. and Bilder, D. 2005. The Drosophila tumor suppressor vps 25 prevents nonautonomous overproliferation by regulating notch trafficking. Dev. Cell 9: 687-698.

van den Heuvel, M. and Ingham, P.W. 1996. smoothened encodes a receptor-like serpentine protein required for hedgehog signalling. Nature 382: 547-551.

Vegh, M. and Basler, K. 2003. A genetic screen for hedgehog targets involved in the maintenance of the Drosophila anteroposterior compartment boundary. Genetics 163: 14271438.

Zhu, A.J., Zheng, L., Suyama, K., and Scott, M.P. 2003. Altered localization of Drosophila Smoothened protein activates Hedgehog signal transduction. Genes \& Dev. 17: 1240-1252. 


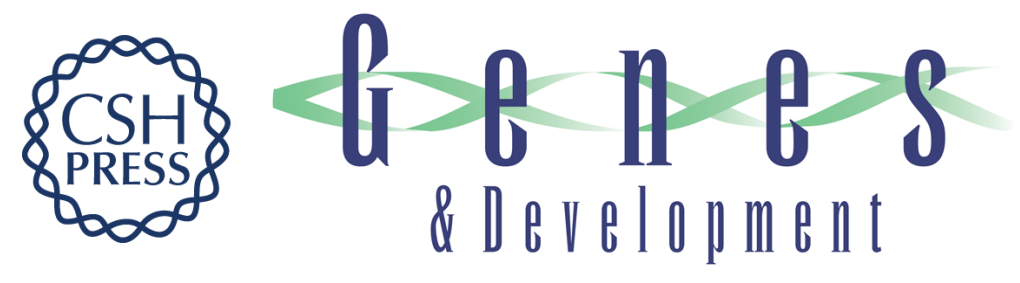

\section{The C-terminal tail of the Hedgehog receptor Patched regulates both localization and turnover}

Xingwu Lu, Songmei Liu and Thomas B. Kornberg

Genes Dev. 2006, 20:

Access the most recent version at doi:10.1101/gad.1461306

Supplemental http://genesdev.cshlp.org/content/suppl/2006/09/18/20.18.2539.DC1
Material

References This article cites 52 articles, 14 of which can be accessed free at:

http://genesdev.cshlp.org/content/20/18/2539.full.html\#ref-list-1

License

Email Alerting

Receive free email alerts when new articles cite this article - sign up in the box at the top

Service

right corner of the article or click here.

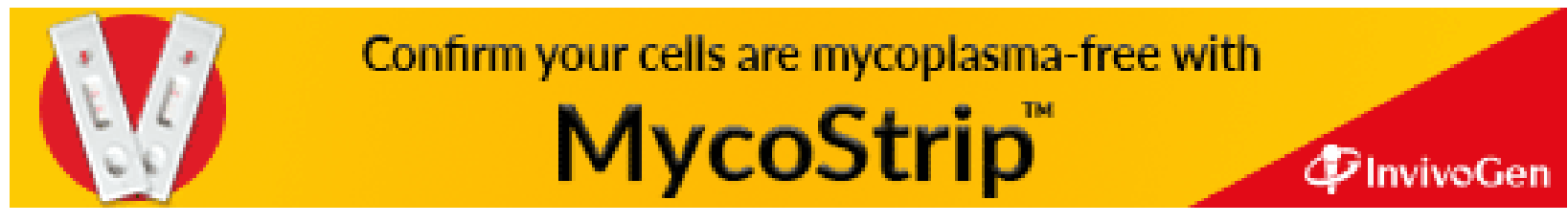

